It is known that actinomycin D blocks the action of parathyroid hormone on bone (Eisenstein et al., 1964; Rasmussen et al., 1964) while not interfering with its actions on renal calcium and phosphate handling. Actinomycin D does not prevent secretion of parathyroid hormone (Tashjiian, 1965). It is possible that the RNA inhibitors act initially by preventing parathyroid hormone induced calcium release from bone, leading to a fall in serum calcium with a resulting increase in parathyroid hormone secretion. This extra parathyroid hormone (unable to act on bone) could be responsible for hypophosphataemia and hypocalciuria, by an action on tubular reabsorption. This aspect may be clarified somewhat by parathyroid hormone assay and studies of renal phosphate clearance.

The similarities between the effects of actinomycin D on our patients, and mithramycin (Ryan and Schwartz, 1969), and the actions of calcitonin in Paget's disease as described by Bijvoet and Jansen (1967) and Bijvoet et al. (1968), suggest that RNA inhibitors may act by potentiating or stimulating the action of calcitonin. Calcitonin assay may shed some light on this aspect.

A direct action of RNA inhibitors on osteoblasts appears quite likely, particularly in view of the findings of reduced formation of chondroitin sulphate in rats treated with actinomycin D (Hulth and Lindberg, 1968) and the finding of inhibition of bone growth in children treated with this agent for renal tumours (Aarskog and Hexeberg, 1968). However, the finding of such a pronounced fall in urinary calcium even after the serum calcium level has returned to normal suggests that a humoral mechanism is also likely to be involved. Actinomycin $\mathrm{D}$ is a toxic drug, a factor which must be a major one in the limitation of the use of this drug in Paget's disease, where long-standing treatment would be required.

\section{References}

Aarskog, A., and Hexeberg, A. (1968). Acta Paediatrica Scandinavica, 57, 463.

Albright, F., and Riefenstein, E. C. (1948). The Parathyroid Glands and Metabolic Bone Disease. Baltimore, Williams \& Wilkins.

Bijvoet, O. L. M., and Jansen, A. P. (1967). Lancet, 2, 471.

Bijvoet, O. L. M., Van der Sluys Veer, J., and Jansen, A. P. (1968). Lancet, 1,876 .

Brown, J. H., and Kennedy, B. J. (1965). New England fournal of Medicine, 272, 111 .

Delsal, J. L., and Manhouri, H. (1958). Bulletin de la Société de Chimie Biologique, 40, 1623.

Eisenstein, et al. (1964). Proceedings of the Society for Experimental Biology, 117,77 .

Fennelly, J. J., Dunne, J., McGeeney, K. F., Lee Chong, L., and Fitzgerald, M. (1969). Annals of New York Academy of Sciences, 166, 794. Hulth; A., and Lindberg, L. (1968). Acta Pathologica et Microbiologica Scandinavica, 73, 177 .

Kirk, J. M. (1960). Biochimica et Biophysica Acta, 52, 167.

Parsons, V., Baum, M., and Self, M. (1967). British Medical fournal, 1, 474. Prockop, D. J., and Udenfriend, S. (1960). Analytical Biochemistry, 1, 228 Rasmussen, H., Arnaud, C., and Hawker, C. (1964). Science, 154, 1019.

Ryan, W. G., and Schwartz, T. B. (1969). Annals of Internal Medicine, 70, 549.

Tambyah, J. A., and Lim, M. K. L. (1969). British Medical fournal, 1, 751. Tan, C. T. C., Dargeon, H. W., and Burchenal, J. H. (1959). Pediatrics,

24, 544.
Tashiian, A. H. (1965). Endocrinology, 77, 375.

Trinder, P. (1960). Analyst, 85, 889.

\title{
Clinical Trial of Malaria Prophylaxis in Tropical Splenomegaly Syndrome
}

\author{
PIETER C. STUIVER, JOHN L. ZIEGLER, JOHN B. WOOD, RICHARD H. MORROW
} M. S. R. HUTT

\section{Introduction}

Tropical splenomegaly syndrome refers to chronic splenomegaly of uncertain cause which has been reported from a number of tropical countries (Pitney, 1968). In Uganda the syndrome was formerly known as "big spleen disease" and has been associated with lymphocytic infiltration of the hepatic sinusoids (Hamilton et al., 1965, 1966; Marsden et al., 1965). Malarial infection has been implicated in its aetiology on the basis of several kinds of indirect evidence. There is a close geographic coincidence of tropical splenomegaly syndrome with malarious areas, and patients having it show high titres of malaria antibodies (Gebbie et al., 1964; Hamilton et al., 1965; Marsden et al., 1967). Sickle-cell trait, which confers considerable protection against severe Plasmodium falciparum malaria, occurs rarely if at all in these patients (Hamilton et al., 1969). More compelling evidence is contained in the reports of improvement in hepatosplenomegaly and anaemia in patients with tropical splenomegaly syndrome following long-term malaria prophylaxis (Lowenthal and Hutt, 1968; Watson-Williams and Allan, 1968; Sagoe, 1970). In order to confirm these reports a double-blind randomized clinical trial using primaquine and chloroquine was carried out in 29 Ugandan patients with tropical splenomegaly syndrome. The results form the basis of the present report. 


\section{Patients and Methods}

A weekly "big spleen clinic" was established at Mulago Hospital in November 1968. Thirty-one patients who met our criteria for tropical splenomegaly syndrome (Hamilton et al., 1965) and who agreed to long-term treatment and follow-up were admitted to the study between November 1968 and September 1969. Two patients were lost to follow-up, leaving 29 evaluable patients: 14 received malaria prophylaxis and 15 received placebo. The two groups are comparable with respect to age, sex, and duration in the trial (Table I).

TABLE I-Comparison of Trial and Control Groups

\begin{tabular}{|c|c|c|c|c|}
\hline & & & Antimalarial & Control \\
\hline $\begin{array}{l}\text { No. of patients } \ldots \\
\text { Male/female } \quad \ldots \\
\text { Median age (years) } \\
\text { Months on trial (median) }\end{array}$ & $\begin{array}{ll}\cdots & \cdots \\
\cdots & \cdots \\
\cdots & \cdots\end{array}$ & $\begin{array}{ll}\cdots & \cdots \\
\cdots & \cdots \\
\cdots & \cdots\end{array}$ & $\begin{array}{ll}14 \\
& 7 / 7 \\
30 & (12-65) \\
10 & (6-14)\end{array}$ & $\begin{array}{ll}15 \\
27 \\
27 / 9 \\
10(13-60) \\
(2-15)\end{array}$ \\
\hline
\end{tabular}

All patients were admitted to Mulago Hospital, where a detailed clinical history was taken and a complete physical examination carried out. The laboratory evaluation included: haemoglobin, W.B.C., differential count, reticulocyte count, thick and thin blood film for malarial parasites, urine analysis, stool examination, liver function studies, malaria antibody and brucella agglutinin tests, haemoglobin electrophoresis, glucose-6-phosphate dehydrogenase (G6PD) determination, chest radiogram, electrocardiogram, and bone-marrow examination when indicated. After appropriate blood-coagulation studies, liver biopsy was performed with a Menghini needle, and the tissue was processed for imprint cytology, routine histology, and electron microscopy.

Criteria for admission to the treatment trial included chronic splenomegaly and sinusoidal lymphocytosis in the liver biopsy specimen. Other causes of splenomegaly (Marsden and Hamilton, 1969) were excluded by appropriate investigations. Patients under 12 years of age were excluded from the study. None of the patients had received previous malaria prophylaxis.

The treatment trial consisted of primaquine $15 \mathrm{mg}$ daily for two weeks (if G6PD was not deficient) and chloroquine phosphate $300 \mathrm{mg}$ base given weekly. The control group received placebo tablets. Tablets sufficient for a one-year trial for 40 patients ( 20 antimalarial, 20 placebo) were divided into 12 -monthly pill containers and coded by random numbers from 1 to 40 . Treatment packages were sequentially allocated to those included in the trial. Patients were carefully instructed in their own language on how to take the medicine, and were asked to repeat the instructions to ensure comprehension.

Patients were seen every two weeks during the first month of the trial and once a month thereafter. At each clinic visit the investigators recorded any symptoms of intercurrent illnesses and assured themselves that the drugs were being taken in accordance with instructions. Spleen size was recorded initially and at each clinic visit by measuring the vertical distance in centimetres from the costal margin at the midclavicular line to a transverse line tangential to the most distant point of the spleen. The percentage change in spleen volume was calculated on the assumption that a barely palpable spleen is a sphere of 9-cm diameter $(400 \mathrm{~g})$ (BruceChwatt, 1956), and that the linear change in centimetres below the costal margin was a change in the diameter (not radius). Liver size was also recorded in centimetres below the right costal margin at the midclavicular line and below the xyphoid. Haemoglobin, W.B.C., differential count, and blood films for malaria parasites were routinely performed at each clinic visit, and other investigations were carried out as
indicated.

\section{Results}

Preliminary results in 16 patients analysed in June 1969 (Wood et al., 1970) showed no significant differences in spleen size reduction or symptomatic improvement between the treatment and control groups. By April 1970, however, 15 months after the trial was started, there were significant differences.

Spleen Size.-The changes in estimated spleen volume in all patients are given in Table II. All 14 patients receiving

\begin{tabular}{|c|c|c|c|c|c|c|c|}
\hline \multicolumn{4}{|c|}{ Malarial Prophylaxis } & \multicolumn{4}{|c|}{ Placebo } \\
\hline \multirow{2}{*}{$\begin{array}{l}\text { Case } \\
\text { No. }\end{array}$} & \multicolumn{2}{|c|}{$\begin{array}{l}\text { cm Splenomegaly } \\
\text { below Costal Margin }\end{array}$} & \multirow{2}{*}{$\begin{array}{c}\text { o } \\
\text { Change } \\
\text { in } \\
\text { Volume* }\end{array}$} & \multirow{2}{*}{$\begin{array}{l}\text { Case } \\
\text { No. }\end{array}$} & \multicolumn{2}{|c|}{$\begin{array}{l}\mathrm{cm} \text { Splenomegaly } \\
\text { below Costal Margin }\end{array}$} & \multirow{2}{*}{$\begin{array}{c}\% \\
\text { Change } \\
\text { in } \\
\text { Volume }\end{array}$} \\
\hline & Before & After & & & Before & After & \\
\hline $\begin{array}{r}30 \\
18 \\
9 \\
22 \\
3 \\
17 \\
20 \\
10 \\
13 \\
29 \\
1 \\
6 \\
8 \\
28\end{array}$ & $\begin{array}{r}10 \\
12 \\
8 \\
18 \\
6 \\
16 \\
11 \\
12 \\
12 \\
12 \\
12 \\
3 \\
10 \\
10\end{array}$ & $\begin{array}{l}0 \\
2 \\
0 \\
6 \\
1 \\
8 \\
5 \\
6 \\
6 \\
6 \\
7 \\
1 \\
7 \\
8\end{array}$ & $\begin{array}{l}-89 \\
-86 \\
-85 \\
-84 \\
-71 \\
-69 \\
-46 \\
-63 \\
-63 \\
-63 \\
-56 \\
-42 \\
-40 \\
-28\end{array}$ & $\begin{array}{r}2 \\
4 \\
25 \\
24 \\
32 \\
16 \\
11 \\
7 \\
15 \\
27 \\
12 \\
23 \\
21 \\
26 \\
14\end{array}$ & $\begin{array}{r}10 \\
21 \\
15 \\
12 \\
13 \\
6 \\
2 \\
8 \\
16 \\
10 \\
8 \\
10 \\
10 \\
11 \\
3\end{array}$ & $\begin{array}{r}6 \\
18 \\
12 \\
11 \\
12 \\
6 \\
2 \\
8 \\
17 \\
11 \\
10 \\
12 \\
12 \\
14 \\
7\end{array}$ & $\begin{array}{r}-50 \\
-37 \\
-32 \\
-14 \\
-13 \\
0 \\
0 \\
0 \\
0 \\
+13 \\
+18 \\
+39 \\
+36 \\
+36 \\
+52 \\
+138\end{array}$ \\
\hline
\end{tabular}

*Calculation of \% spleen volume change as foltows (also see text): cm splenomegaly after trial $=\mathrm{S1}$; cm splenomegaly before trial $=$ So

$$
\because \Delta \mathrm{V}=\frac{\left(\frac{\text { S1 }+9}{2}\right)^{3}-\left(\frac{\text { So }+9}{2}\right)^{2}}{\left(\frac{\text { So }+9}{2}\right)^{3}} \times 100
$$

malaria prophylaxis had significant reduction in splenomegaly; in 11 this was by more than $50 \%$ of the original spleen volume. No control patient's spleen was reduced by more than $50 \%$. There were no sex differences in responsiveness to antimalarials, but younger patients responded significantly better than older ones (Table III) $(P<0.05$,

TABLE III-Relationship of Spleen Size Reduction to Age in Patients Receiving Antimalarials

\begin{tabular}{|c|c|c|c|c|c|}
\hline Case No. & & & Age & Sex & $\%$ Volume Reduction \\
\hline $\begin{array}{r}22 \ldots \\
9 \\
10 \\
17 \\
30 \\
18 \\
18 \\
20 \\
13\end{array}$ & $\begin{array}{l}\cdots \\
\cdots \\
\cdots \\
\cdots \\
\cdots \\
\cdots \\
\cdots \\
\cdots \\
\cdots \\
\cdots\end{array}$ & $\begin{array}{l}\ldots \\
\cdots \\
\cdots \\
\cdots \\
\cdots \\
\cdots \\
\cdots \\
\cdots \\
\cdots \\
\cdots\end{array}$ & $\begin{array}{l}12 \\
13 \\
14 \\
18 \\
21 \\
29 \\
30 \\
35 \\
38 \\
45 \\
48 \\
50 \\
60 \\
65\end{array}$ & $\begin{array}{c}\text { M. } \\
\text { F. } \\
\text { F. } \\
M . \\
F . \\
F . \\
M . \\
F . \\
F . \\
F . \\
M . \\
M . \\
M . \\
M .\end{array}$ & $\begin{array}{r}84 \\
-85 \\
-63 \\
-69 \\
-89 \\
86 \\
-66 \\
-63 \\
-28 \\
63 \\
40 \\
56 \\
42 \\
-71\end{array}$ \\
\hline
\end{tabular}

Spearman rank correlation coefficient $\mathrm{r}_{\mathrm{S}}=0.55 ; \mathrm{P}-0.05$

Spearman rank correlation coefficient $r_{*}=0.55$ ). In addition, the younger patients tended to have larger spleens, though in this small group the relationship was not statistically significant $(P<0 \cdot 1$. Spearman rank correlation coefficient $\left.\mathrm{r}_{\mathrm{s}}=0.46\right)$. Splenomegaly in the control patients decreased slightly in three, remained unchanged $( \pm 20 \%$ in estimated volume change) in seven, and increased in volume in five (see Table II). The progression of splenomegaly in the control group was not related to age, sex, or duration of observation. The splenic volume reduction in patients receiving antimalarials is shown in the Chart. Though there is some asymptotic flattening of the curve, the spleens are continuing to become smaller. Hepatomegaly was not a prominent feature in this series of patients with tropical splenomegaly syndrome, and significant changes were not observed in liver size during the study. 


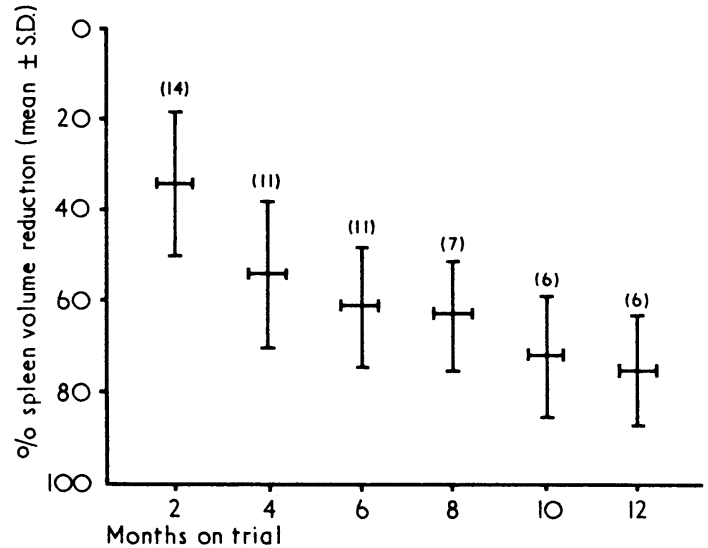

Time course of spleen volume reduction in patients receiving antimalarials. Figures in parentheses refer to patients observed at each interval.

Symptoms.-At the end of the trial patients were asked whether they felt better, the same, or worse since the trial began. The assessment of symptoms included feeling of wellbeing, appetite, fatigue, weakness, fevers, and splenic pain. In general, patients initially sought help for two different reasons: most complained of chronic abdominal discomfort directly attributable to the large spleen, whereas some had symptoms of anaemia. Relief of symptoms (Table IV) was

TABLE IV-Symptomatic Improvement During the Study Period

\begin{tabular}{|c|c|c|c|c|c|c|c|c|c|}
\hline & & & & & & & & \multicolumn{2}{|c|}{ No. of Patients } \\
\hline & & & & & & & & Antimalarial & Control \\
\hline \multirow[t]{2}{*}{$\begin{array}{l}\text { Better } \\
\text { Same } \\
\text { Worse }\end{array}$} & $\begin{array}{l}\ldots \\
\cdots \\
\cdots\end{array}$ & $\begin{array}{l}. . \\
\cdots\end{array}$ & $\begin{array}{l}\ldots \\
\cdots\end{array}$ & $\begin{array}{l}\ldots \\
\cdots\end{array}$ & $\begin{array}{l}\ldots \\
\cdots \\
\cdots\end{array}$ & $\begin{array}{l}\ldots \\
\cdots \\
\cdots\end{array}$ & $\begin{array}{l}\ldots \\
\cdots \\
\ldots\end{array}$ & $\begin{array}{c}10(71 \%) \\
4(29 \%) \\
0\end{array}$ & $\begin{array}{r}2(13 \%) \\
10(67 \%) \\
3(20 \%)\end{array}$ \\
\hline & & & & & & & & 14 & 15 \\
\hline
\end{tabular}

significantly greater in the treatment group than in controls $\left(\mathrm{P}<0.01\right.$ by $\left.\chi^{2}\right)$.

Haemoglobin.-Changes in haemoglobin levels before and on completion of the trial showed improvement in the treatment group $(P<0.05$, Mann Whitney $U$ test) (Table $V$ ).

TABLE v-Changes in Haemoglobin Levels During Study Period

\begin{tabular}{|c|c|c|c|c|c|c|c|c|}
\hline \multicolumn{7}{|c|}{ Changes in Haemoglobin $(\mathrm{g} / 100 \mathrm{ml})$} & \multicolumn{2}{|c|}{ No. of Patients } \\
\hline & & & & & & & \multirow{2}{*}{$\begin{array}{|cc|}\text { Antimalarial } \\
3 & (21 \%) \\
5 & (35 \%) \\
5 & (35 \%) \\
1 & (7 \%)\end{array}$} & \multirow{2}{*}{\begin{tabular}{cc}
\multicolumn{2}{c}{ Control } \\
1 & $(7 \%)$ \\
2 & $(14 \%)$ \\
6 & $(40 \%)$ \\
6 & $(40 \%)$
\end{tabular}} \\
\hline $\begin{array}{l}\text { Increase } \\
\text { No change } \\
\text { Decrease }\end{array}$ & $\left\{\begin{array}{c}3+ \\
1-2 \cdot 9 \\
\pm 1 \\
1-2 \cdot 9\end{array}\right.$ & $\begin{array}{l}\cdots \\
\cdots \\
\cdots\end{array}$ & $\begin{array}{l}\cdots \\
\cdots \\
\cdots \\
\cdots\end{array}$ & $\begin{array}{l}\cdots \\
\cdots \\
\cdots\end{array}$ & $\begin{array}{l}\cdots \\
\cdots \\
\cdots\end{array}$ & $\begin{array}{l}\cdots \\
\cdots \\
\cdots\end{array}$ & & \\
\hline
\end{tabular}

None of the patients in the study had G6PD deficiency. Haemoglobin levels in the control group did not improve, but tended to decline. None of the patients had significantly depressed W.B.C. or platelet counts initially and there were no changes with antimalarials.

Parasitaemia.-On initial examination 4 out of 14 who were put on malaria prophylaxis and 2 out of 15 in the control group had scanty $P$. falciparum parasitaernia. Occasional parasites were seen in the control group during the study, but in neither group were there clinical attacks of acute malaria.

\section{Discussion}

This study confirms the clinical effectiveness of prolonged malaria prophylaxis in the treatment of tropical splenomegaly syndrome. As in the experience of West African investigators (Watson-Williams and Allan, 1968; Sagoe, 1970) long-term therapy is necessary before definite clinical responses are observed. Significant reduction in spleen size, substantial symptomatic relief, and improvement in haemoglobin levels were found. Further analysis of the patients who responded to malaria prophylaxis showed that younger patients responded better than older ones. The poorer response in the elderly may be related to secondary changes, such as fibrosis and adhesions in spleens which have been enlarged for many years.

Our study differed from that carried out in West Africa as follows: (1) primaquine and chloroquine rather than proguanil were used, (2) the design of the two trials was different, (3) the criteria for patient selection in our series included hepatic sinusoidal lymphocytosis, and (4) the degree of splenomegaly and haematological abnormalities was less pronounced than in the West African patients. Nevertheless, the studies have shown that two different malarial prophylactic regimens will produce substantial improvement in tropical splenomegaly syndrome.

As soon as the results of this trial were analysed and significant differences were observed, those receiving placebo tablets were placed on primaquine and chloroquine. Six thus far evaluated have already shown substantial reduction of spleen size over a period of six months. The spleen size reduction time curves of most of our treated patients were still continuing downward after 12 months of therapy, and it seems clear that continued malaria prophylaxis is required. The optimal duration of antimalarial administration required for control of tropical splenomegaly syndrome has yet to be established. Both in our experience and in that from West Africa patients have relapsed after discontinuing their medication even after long periods of successful treatment. It may be that patients require prophylaxis as long as they remain exposed to malarial infection.

The pathogenesis of tropical splenomegaly syndrome and its relation to malaria is still unclear. These patients appear to have generally normal immune responses (Ziegler et al., 1969), but produce a large amount of macroglobulin (Wells, 1968). Electron microscopy studies of the liver have shown mature lymphocytes in close association with hypertrophied Kupffer cells, an appearance which is very suggestive of a cellular immune response (Hutt and Fluck, 1970). These observations have led to speculation that there is a persistent antigenic stimulus which results in a benign lymphoproliferative disorder predominately affecting the spleen and liver. The stimulus may be due to the malaria parasite itself, malaria antigen in an altered form, or possibly even to a form of malaria antibody. As malaria parasite frequency and density rates are very low in this condition and overt attacks of malaria are very rare, the immune response can be said to be effective in this respect.

In any event, if chronic malarial parasitaemia of a very low grade provides the antigenic stimulus leading to tropical splenomegaly syndrome, then the beneficial effect of malaria prophylaxis can be readily accounted for by the elimination of parasites from the blood. This seems to be the simplest explanation of the clinical observations at present.

The best treatment for tropical splenomegaly syndrome has not been fully settled. Splenectomy should be reserved, at least in the tropics, for special indications (Hamilton et al., 1967; Paliwoda and Hutt, 1968). It is possible that more potent cytotoxic agents such as methotrexate or chlorambucil have a role in severe hypersplenism in which splenectomy cannot be performed. Prolonged therapy with antimalarial drugs (chloroquine or proguanil), however, seems to be the most reasonable and effective treatment for uncomplicated cases of tropical splenomegaly syndrome at the present time.

We wish to thank Mrs. Dumba, Mrs. I. J. Stuiver, Mr. David Kivumbe, Dr. Sam Banyikidde, and Dr. Christina Templeton for help in the clinical care of the patients. Mr. John Kyobe and $\mathrm{Mr}$. 
J. W. Wamboka provided valuable technical help. The chloroquine phosphate and placebo tablets were kindly provided by May and Baker Ltd. This study was supported in part by Contract No. PH 43-67-47 and PH 43-67-1343 from the National Cancer Institute, Bethesda, Md., and by funds from Makerere University College $(438 / 69)$.

\section{References}

Bruce-Chwatt, L. J. (1956). Bulletin of the World Health Organization, $15,513$.

Gebbie, D. A. M., et al. (1964). Lancet, 2, 392.

Hamilton, P. J. S., Gebbie, D. A. M., Hutt, M. S. R., Lothe, F., and Wilks, N. E. (1966). British Medical fournal, 2, 548

Hamilton, P. J. S., et al. (1965). East African Medical fournal, 42, 191.

Hamilton, P. J. S., et al. (1967). British Medical fournal, 3, 823.
Hamilton, P. J. S., et al. (1969). Lancet, 2, 209.

Hutt, M. S. R. and Fluck, C. (1970). Unpublished observations. Lowenthal, M. N., and Hutt, M. S. R. (1968). East African Medical fournal, $45,100$.

Marsden, P. D., et al. (1965). British Medical fournal, 1, 89.

Marsden, P. D., et al. (1967). Bulletin of the World Health Organization, (a)

36, 901 .

Marsden, P. D., and Hamilton, P. J. S. (1969). British Medical fournal, 1, 99 Paliwoda, T., and Hutt, M. S. R. (1968). East African Medical fournal, 45, 1 .

Pitney, W. R. (1968). Transactions of the Royal Society of Tropical Medicine and Hygiene, 62, 717.

Sagoe, A. (1970). British Medical fournal, 3, 378.

Watson-Williams, E. J., and Allan, N. C.' (1968). British Medical fournal, 4, 793.

Wells, J. V. (1968). Clinical and Experimental Immunology, 3, 943.

Wood, J. B., et al. (1970). East African Medical fournal, 47, 191.

Ziegler, J. L., Cohen, M. H., and Hutt, M. S. R. (1969). British Medical fournal, 4, 15.

\title{
Tropical Splenomegaly Syndrome in Zambia: Further Observations and Effects of Cycloguanil and Proguanil
}

\author{
M. N. LOWENTHAL, E. C. O'RIORDAN, M. S. R. HUTT
}

British Medical fournal, 1971, 1, 429-432

\section{Summary}

Nineteen Zambian patients with the tropical splenomegaly syndrome and sinusoidal lymphocytosis on liver biopsy were studied. The association of macrobulinaemia with the tropical splenomegaly syndrome has again been confirmed. Sixteen patients were treated with antimalarials-12 with cycloguanil pamoate alone, 3 with cycloguanil and proguanil, and 1 with proguanil alone. Twelve patients were observed for periods of sufficient length for the drug effect to be assessed, and in 11 there was a good response in terms of decrease in spleen size.

Cycloguanil pamoate may be of value both for prophylaxis and treatment in areas where tropical splenomegaly syndrome is endemic.

\section{Introduction}

The tropical splenomegaly syndrome has been the subject of several reviews during the past two years (Pitney, 1968; British Medical fournal, 1967, 1969). Previous studies in Zambia showed that tropical splenomegaly syndrome occurring there was similar to that described in other parts of Africa (Lowenthal et al., 1966) and also that long-term antimalarial prophylaxis with proguanil was beneficial (Lowenthal and Hutt, 1968). Similar results, with more complete remissions, have been found in two larger series of cases treated with proguanil in Nigeria (Watson-Williams and Allan, 1968; Sagoe, 1970). A double-blind trial on cases of tropical splenomegaly syndrome in Uganda with long-term chloroquine therapy has also shown significant improvement in patients' symptoms and spleen size (Stuiver et al., 1971). Earlier experience with long-term treatment with proguanil

\section{Central Fospital. Ndola, Zambia}

M. N. LOWENTHAL, M.B., M.R.C.P.ED., Physician Specialist

E. C. O'RIORDAN, M.B., B.SC.(PATH.), Specialist Pathologist

\section{St. Thomao's Hoopital Medical School, London S.E.1}

M. S. R. HUTT, M.D., F.R.C.P., F.R.C.PATH., Professor of Geographical Pathology showed that it was not always easy to ensure that the drug was continually taken over a long period of time. For this reason it was decided to treat cases of tropical splenomegaly syndrome with the depot injectable antimalarial cycloguanil pamoate (Camolar) either alone or in some cases combined with proguanil.

\section{Patients and Methods}

Nineteen patients (13 male and 6 female) who fulfilled the diagnostic criteria for tropical splenomegaly syndrome (Marsden and Hamilton, 1969) were admitted to the wards of the Ndola Central Hospital during the period December 1968 to March 1970. In all cases a detailed clinical history and physical examination were carried out. Spleen size was measured along the longest palpable axis of the organ. All clinical examinations were made by one of us (M.N.L.). Laboratory examinations included: haemoglobin, white count and differential, thick blood film for malarial parasites, urine analysis and stool examination for parasites in all cases, haemoglobin electrophoresis in 14 patients, and sternal marrow puncture in 12 patients. Percutaneous liver biopsy was performed in all 19 patients and the diagnosis of tropical splenomegaly syndrome with hepatic sinusoidal lymphocytosis was established according to previous criteria (Marsden et al., 1967). Repeat liver biopsies were done in five patients at intervals after treatment had started. Other investigations, including plasma protein levels, empirical liver function tests, agglutinations against brucella and salmonella organisms, serum iron levels, and chest $x$-ray examination, were done in most cases.

Immunological Studies.-IgM levels were measured in 17 cases by a modification of the method of Mancini et al. (1965). The assay was repeated in seven cases after therapy, and in three of these a third estimation was made after a further interval. For the purpose of providing control values IgM was assayed in two other groups of patients. The first included patients with moderate to massive splenomegaly due to chronic myeloid leukaemia ( 3 cases), primary myeloid metaplasia (2), schistosomiasis (5), tropical splenomegaly syndrome without hepatic sinusoidal lymphocytosis (4), hepatic cirrhosis (6), and one case each of tuberculosis, amyloidosis, and con- 